\title{
KAJIAN POTENSI PEMBENTUKAN AIR ASAM TAMBANG DARI TANAH LAPISAN PENUTUP BATUBARA ASAL KABUPATEN TELUK BINTUNI
}

(The Study of Acid Mine Drainage Potential Formation of the Coal Overburden Materials from the Bintuni Regency)

\section{Markus Heryanto Langsa ${ }^{1 *}$}

${ }^{1}$ Jurusan Kimia, Fakultas Matematika dan Ilmu Pengetahuan Alam, UNIPA, Manokwari, 98314, Indonesia

*Korespondesi: m.langsa@unipa.ac.id

\begin{abstract}
Acid mine drainage is formed when certain sulfide minerals in rocks are exposed to oxidizing. Upon exposure to oxidizing conditions, these sulfide minerals are oxidized in the presence of water and oxygen to form highly acidic, sulfate-rich drainage. Acidity levels, and metal composition and concentration depend on the type and amount of sulfide mineral and the presence or absence of alkaline materials. If acid mine drainage has formed, it will be very difficult to stop the process as it is a continuous process until one of the reactions runs out. Acidic water containing heavy metals when flowing into rivers, loker or swamps will damage the condition of the ecosystem in the river. This will certainly cause a decrease in water quality. The purpose of this study is to examine the potential for the formation of acid mine drainage based on the acid base balance method. The results obtained in samples $A, B 1, B 2$, and $C$ for the pasta $p H$ test were 5.25, 4.20, 4.71 , and 3.14 , respectively. The results of the other parameters for the four samples were total sulfur contents $(0.005 \%, 0.021 \%, 0.008 \%, 0.47 \%)$, acid neutralization ability (3.1, $2.82,2.45,13.07 \mathrm{~kg} \mathrm{H}_{2} \mathrm{SO}_{4} /$ ton), maximum acidic potential $(0.153,0.643,0.245,14.394$ $\mathrm{kg} \mathrm{H}_{2} \mathrm{SO}_{4} /$ ton) and acid-base balance expressed as potential acid production (-12.917, 2.177, -3.065, 11,944). Evaluation of sample $C$ data based on acid-base balance values $\left(11.944 \mathrm{~kg} \mathrm{H}_{2} \mathrm{SO}_{4} /\right.$ ton) and $\mathrm{KPA} / \mathrm{PKM}$ ratio $(<2,0.17)$ indicating that sample $C$ has the potential to form acid mine drainage if the coal mining process is carried out.
\end{abstract}

Keyword: Acid Mine, Drainage Potential Formation, Coal Overburden Materials

\section{PENDAHULUAN}

Batubara merupakan mineral yang tersusun atas karbon, hidrogen, oksigen, nitrogen, belerang, dan senyawa-senyawa minerallain yang dapat digunakan sebagai sumber energi (Kent, 1993). Empat puluh persen (40\%) pembangkit listrik di dunia menggunakan energi yang 
berasal dari batubara (Syarif etal, 2014). Batubara juga merupakan bahan bakar utama bagi produksi Indonesia merupakan salah satu daerah penghasil tambang batubara terbesar di dunia. Batubara banyak ditemukan di Indonesia seperti Jawa, Kalimantan, Sumatera, Sulawesi, Maluku, dan Papua. Menurut Kementerian ESDM (2011) kandungan batubara di Indonesia sebesar 105.187,44 juta ton yang tersebar di beberapa wilayah di antaranya Sumatra 52.483,20 juta ton, Kalimantan $52.326,23$ juta ton, Sulawesi 233,10 juta ton, Papua 128,57 juta ton, dan Jawa 14,21 juta ton.

Kegiatan penambangan batubara berdampak terhadap penurunan komponen lingkungan hidup terutama kualitas air. Pada saat penambangan, penggalian batubara dapat mempercepat proses pembentukan air asam tambang (AAT) yang mengandung logamlogam berat seperti $\mathrm{Mn}, \mathrm{Mg}, \mathrm{Cu}, \mathrm{Fe}$ jika keberadaannya melebihi ambang batas akan bersifat toksik terhadap lingkungan. Selain itu, pembakaran batubara yang mengandung kadar belerang tinggi, dapat menghasilkan baja, semen, dan kegiatan-kegiatan industri lainnya (Anonim, 2005).

polutan udara, seperti belerang dioksida, yang dapat menyebabkan terjadinya hujan asam. Karbon dioksida yang terbentuk pada saat pembakaran juga berdampak negatif pada lingkungan udara (Achmad, 2004).

Pertumbuhan industri di daerah Teluk Bintuni semakin meningkat dimana hampir seluruh wilayah Kabupaten Teluk Bintuni memiliki potensi tambang batubara yang besar (BPS 2012). Batubara umumnya diperoleh dengan cara menggali tanah lapisan penutup batubara yang mengandung mineral sulfida dimana mineral tersebut dapat teroksidasi dan bersifat toksik bagi lingkungan. Potensi terbentuknya AAT dalam suatu wilayah tambang batubara tergantung pada kandungan belerang dan jenis mineral oksida tanah lapisan penutup batubara. Kualitas batubara di Kabupaten Teluk Bintuni adalah kualitas premium dengan nilai kalori di atas 16.800 joule dengan kandungan belerang yang tergolong rendah $(0,3-1,4 \%)$. Walaupun memiliki kadar belerang yang 
tergolong rendah, potensi terbentuknya AAT saat penggalian batubara tetap ada karena adanya pembukaan tanah lapisan penutup batubara perlu di lakukan untuk melengkapi studi kelayakan dari investor batubara mengenai dampak penambangan batubara terhadap komponen lingkungan, terutama air di sekitar lokasi penambangan. Oleh

\section{METODE}

\section{Bahan Kimia}

Semua bahan kimia/reagen anorganik yang digunakan pada penelitian ini adalah kualitas pro analisis.

\section{Prosedur Kerja}

Uji pH pasta (Sobek, 1978)

Pengukuran $\mathrm{pH}$ pasta dilakukan mengacu pada Sobek (1978) dimana rasio sampel:air destilasi adalah 2:1. Nilai $\mathrm{pH}$ pasta diukur menggunakan pH meter HQ 40D HACH.

\section{Total Belerang}

Kandungan total belerang pada sampel dianalisis menggunakan Metoda Eschka secara gravimetri. Sampel tanah sebanyak $10,0 \mathrm{~g}$ dimasukkan ke cawan crucible dan mineral-mineral sulfida pada tanah lapisan penutup batubara. Kajian potensi terbentuknya AAT dari karena itu, perlu dilakukan penelitian mengenai kajian potensi terbentuknya AAT dari pembukaan tanah lapisan penutup batubara asal kabupaten teluk bintuni dan analisis kadar logam berat (seperti Fe, Mn dan $\mathrm{Cu}$ ) yang terkandung pada AAT. dan dicampur dengan campuran Eschka yaitu campuran antara $\mathrm{MgO}$ dan $\mathrm{NaCO}_{3}$ anhidrat (2:1) yang kemudian dipanaskan pada suhu $820^{\circ} \mathrm{C}$ selama 2 jam.

\section{Kapasitas Penetralan Asam, KPA} (Acid Neutralization Potential)

Sampel ditimbang seberat 0,5 gram dengan ukuran sampel 60 mesh dan diletakkan pada alumunium foil. Tambahkan 1 atau 2 tetes $\mathrm{HCl}$ 1:3 pada sampel. Timbulnya busa atau terdengarnya bunyi "fizz" menandakan adanya $\mathrm{CaCO}_{3}$ pada sampel.Selanjutnya cocokan tingkat busa atau bunyi "fizz" yang terbentuk dengan Tabel 1. 
Tabel 1: Perbandingan $\mathrm{HCl}$ dan $\mathrm{NaOH}$

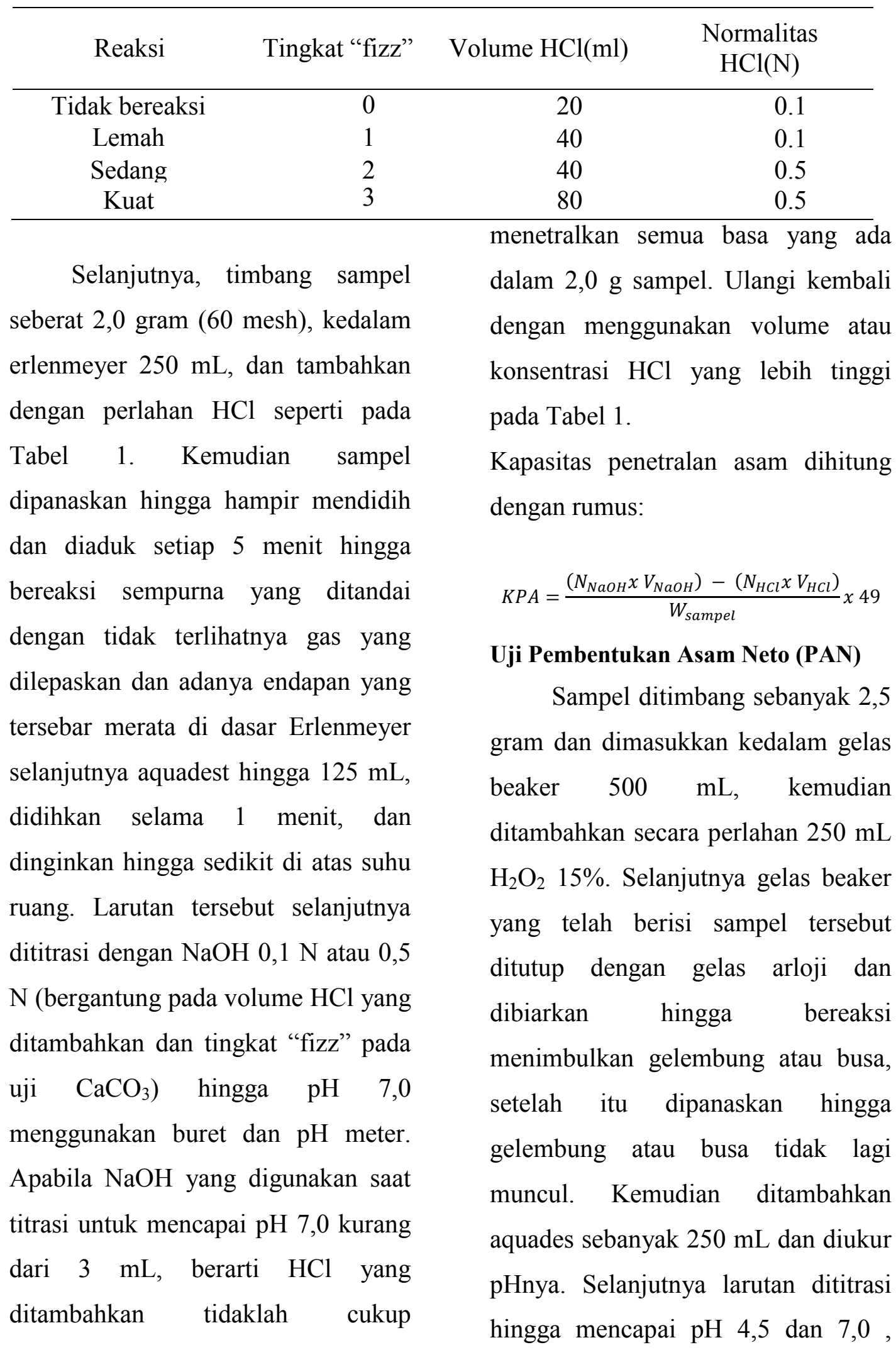


apabila pH sampel lebih dari 2 maka dititrasi dengan menggunakan $\mathrm{NaOH}$ 0,1 M, apabila sama dengan 2 maka dititrasi menggunakan $\mathrm{NaOH} 0,5 \mathrm{M}$. Kadar PAN dihitung menggunakan rumus:

$$
\mathrm{PAN}=\frac{(49 x V x M)}{W}
$$

cara menghitung Potensi Maksimal Keasaman (PMK), Potensi Menghasilan Asam Neto (PMAN), dan Rasio Potensi Penetralan (RPP). PMK, PMAN dan Potensi Penetralan Asam (PNA)dihitung dengan mengunakan rumus:

$$
\text { PMK }=30.625 \times \%
$$

Belerang

$$
\text { PMAN }=\text { PMK - }
$$

PNA

$$
\mathrm{RPP}=\mathrm{PNA} / \mathrm{PMK}
$$

Dimana apabila rasio potensi penetralan bernilai kurang dari 1

\section{Neraca Asam Basa (NAB)}

Neraca asam basa merupakan metode untuk mengetahui keseimbangan antara proses pembentukan asam dan faktor utama terjadinya asam, yaitu dengan

maka dikatakan berpotensi membentuk asam, 1-2 zona tidak pasti, dan lebih dari 2 tidak berpotensi membentuk asam.

\section{HASIL DAN PEMBAHASAN}

\section{Deskripsi Sampel}

Pengambilan sampel menggunakan bor tanah dilakukan pada kedalaman tanah maksimal $120 \mathrm{~cm}$. Jenis sampel dan lokasi pengambilan sampel dapat dilihat pada Tabel 2 .

Tabel 2: Jenis sampel dan lokasi sampling

\begin{tabular}{|l|l|l|}
\hline Kode Sampel & Jenis Sampel & Titik Koordinat \\
\hline A & Top Soil & $\begin{array}{l}\text { LS: } 01^{\circ} 42^{\prime} 3,66^{\prime} \\
\text { BT: } 133^{\circ} 52^{\prime} 47,22^{\prime}\end{array}$ \\
\hline B1 & Tanah Lapisan Penutup & LS: $01^{\circ} 55^{\prime} 21,72^{\prime}$ \\
& Batubara (overburden) & BT: $133^{\circ} 49^{\prime} 15,24^{\prime \prime}$ \\
\hline B2 & Tanah Lapisan Penutup & LS: $01^{\circ} 47^{\prime} 32,7^{\prime}$ \\
& Batubara (overburden) & BT: $133^{\circ} 41^{\prime} 11,9^{\prime}$ \\
\hline C & Batubara (premature) & LS: $01^{\circ} 55^{\prime} 21,72^{\prime \prime}$ \\
& & BT: $133^{\circ} 49^{\prime} 15,24^{\prime}$ \\
\hline
\end{tabular}


penutup batubara menghasilkan asam

Tabel 3.

asam tambang disajikan pada

Tabel 3: Nilai pH pasta sampel tanah

\begin{tabular}{|c|c|c|c|c|c|c|}
\hline $\begin{array}{c}\text { Kode } \\
\text { Sampe } \\
\text { l }\end{array}$ & $\begin{array}{c}\text { pH } \\
\text { pasta }\end{array}$ & $\begin{array}{c}\text { Total } \\
\text { sulfur }\end{array}$ & KPA & PAN & PKM & PPAN \\
\hline A & 5,25 & 0,005 & 13,07 & - & 0,153 & $-12,917$ \\
\hline B1 & 4,20 & 0,021 & 2,82 & 66,64 & 0,643 & $-2,177$ \\
\hline B2 & 4,71 & 0,008 & 3,1 & - & 0,245 & $-3,065$ \\
\hline C & 3,14 & 0,47 & 2,45 & 335,16 & 14,394 & 11,944 \\
\hline
\end{tabular}

KPA: Kapasitas Penetralan Asam, kg $\mathrm{H}_{2} \mathrm{SO}_{4} /$ ton

PAN: Potensi Asam Netto, kg $\mathrm{H}_{2} \mathrm{SO}_{4} /$ ton

PKM: Potensi Keasaman Maksimum, $\mathrm{kg} \mathrm{H}_{2} \mathrm{SO}_{4} /$ ton

PPAN: Nilai Potensi Produksi Asam, $\mathrm{kg} \mathrm{H}_{2} \mathrm{SO}_{4} / \mathrm{ton}$

Uji pH pasta adalah salah satu metode uji pembentukan air asam tambang yang sangat sederhana. Metoda ini memberikan gambaran terhadap reaksi langsung ketika mineral sulfida terkontak langsung dengan air dan oksigen. Jika mineral sulfida cukup reaktif, maka $\mathrm{pH}$ pasta akan menujukkan nilai $\mathrm{pH}$ yang rendah. Nilai $\mathrm{pH}$ sampel berkisar antara 3,14 - 5,25. Nilai $\mathrm{pH}$ pada kisaran ini dikategorikan sebagai $\mathrm{pH}$ asam hingga asam lemah. Nilai $\mathrm{pH}$ pada sampel $\mathrm{C}$ paling rendah dibandingkan dengan sampel lain karena hanya mengandung asamasam anorganik saja (dalam hal ini asam sulfat hasil oksidasi dari senyawa sulfida). Sampel tanah lainnya yang merupakan tanah lapisan penutup dan top soil masih mengandung asam-asam organic hasil penguraian senyawa organic yang ada di dalam tanah.

Total sulfur yang didapatkan pada sampel berkisar antara 0,005 0,47\%. Dengan demikian banyaknya asam sulfat yang dapat dihasilkan mengacu pada kandungan total sulfur pada sampel tanah adalah berkisar antara $0,15-14,4 \mathrm{~kg} /$ ton. Sulfur yang terkandung pada sampel tanah merupakan nilai total dari beberapa bentuk sulfur berupa organik dan anorganik sulfur (sulfat dan pirit). Rendahnya total sulfur pada sampel A, B1 dan B2 mengindikasikan rendahnya sulfur anorganik sehingga saat tanah lapisan ini dikeruk dan dipindahkan ke lokasi penampungan, 
oksidasimineral sulfida bukan merupakan proses yang dominan dan tidak berpotensi menghasilkan air asam. Sebaliknya total sulfur yang terkandung pada sampel C didominasi surfur anorganik seperti sulfat dan pirit sehingga rentan mengalami oksidasi pada kondisi yang ideal. Nilai sulfur yang tinggi

dipanaskan dalam waktu tertentu agar asam klorida dapat bereaksi dengan sampel. Selanjutnya campuran sampel dititrasi dengan $\mathrm{NaOH}$ hingga $\mathrm{pH}$ yang diinginkan. Data pada Tabel 3 memperlihatkan bahwa KPA dari sampel tanah berkisar antara 2,45 - 13,07 kg/ton. Sampel tanah A memiliki kapasitas penetralan asam yang paling tinggi dari antara sampel tanah lainnya. Dengan nilai KPA yang tinggi, tanah A memiliki kandungan mineral tanah yang mampu menetralkan potensi air asam yang terbentuk dari oksidasi mineral sulfide yang dimilikinya. Dengan demikian dapat disimpulkan bahwa semakin tinggi nilai penetralan, semakin sedikit bahan yang dibutuhkan untuk peningkatan $\mathrm{pH}$. pada sampel $\mathrm{C}$ juga sesuai dengan nilai $\mathrm{pH}$ nya yang rendah.

Kapasitas penetralan asam (KPA) suatu sampel merupakan salah satu indikator dalam menentukan potensi pembentukan air asam pada sampel. Penetralan dapat dilakukan dengan cara penambahan asam klorida $(\mathrm{HCl})$ kedalam sampel, kemudian

Uji potensi asam neto (PAN) bertujuan untuk melihat tingkat keasaman pada sampel. Selain penggunaan rumus matematis untuk menentukan nilai PAN, terdapat kesepakatan penentuan nilai PAN berdasarkan nilai $\mathrm{pH}$ pasta. Jika nilai $\mathrm{pH}$ pasta $>4,5$ kecil kemungkinan terbentuk AAT sehingga nilai PAN hanya ditentukan untuk sampel dengan nilai $\mathrm{pH}$ pasta $<4,5$. Hasil yang didapatkan (Tabel 3) yaitu $66,64 \mathrm{~kg} /$ ton dan $335,16 \mathrm{~kg} / \mathrm{ton}$ masing-masing untuk sampel tanah B1 dan C. Nilai PAN sampel C memberikan konfirmasi besarnya potensi sampel tersebut yang merupakan jenis batubara muda (premature) untuk menghasilkan AAT jika mengalami oksidasi dalam kondisi berair. Hal ini didukung oleh 
data $\mathrm{pH}$ pasta yang rendah $(<4,5)$ dan kandungan total sulfur yang tinggi $(0,47 \%)$ dan kemampuan penetralan asam yang kecil.

\section{Evaluasi Potensi Pembentukan}

\section{AAT}

Neraca asam-basa sering digunakan untuk mengevaluasi keseimbangan AAT didasarkan pada nilai potensi produksi asam (PPAN). Semakin positif nilai PPAN, semakin besar terlihat bahwa nilai PPAN terbentuknya asam sulfat pada sampel C adalah sebesar 11,944 $\mathrm{kg}$ /ton. Nilai ini merupakan konfirmasi dari hasil pengujian lainnya seperti kandungan total sulfur dan PKM bahwa sampel $\mathrm{C}$ berpotensi kuat menghasilkan AAT sehingga perlu mendapat penanganan yang baik saat kegiatan operasi penambangan batubara

Nilai perbandingan/rasio kapasitas penetralan asam terhadap potensi antara proses pembentukan asam dan faktor utama terjadinya asam. Hal ini melibatkan potensi keasaman maksimum (PKM) dan kapasitas penetralan asam (KPA). Evaluasi penentuan sampel tanah berpotensi menghasilkan

potensinya menghasilkan AAT. Berdasarkan nilai parameter neraca asam-basa pada Tabel 3 keasaman maksimum (rasio KPA/PKM) juga digunakan sebagai indikator potensi suatu sampel tanah menghasilkan AAT. Rasio KPA/PKM yang besar menandakan kandungan material/batuan yang berpotensi untuk menetralkan asam sangat tinggi sehingga bahan tersebut akan tetap berkadar $\mathrm{pH}$ mendekati netral dan tidak menimbulkan masalah air asam tambang. Nilai KPA/KPM dari keempat sampel ditunjukkan pada Gambar 1. 


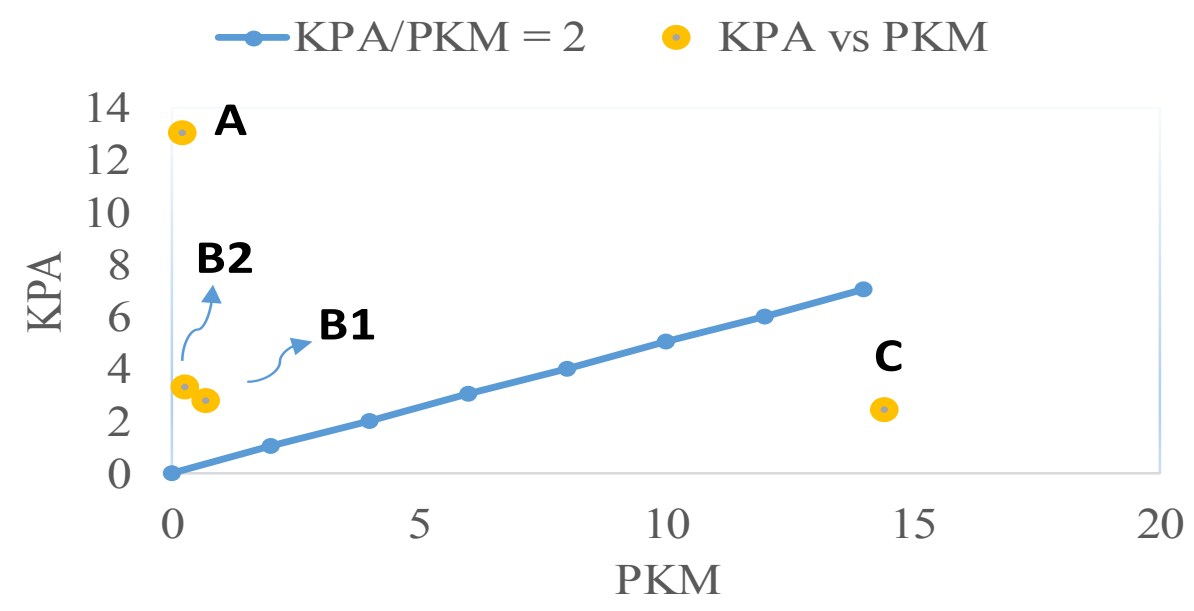

Gambar 1. Hubungan antara KPA dan KPM dari keempat sampel tanah

Rasio KPA/PKM lebih besar dari 2 menunjukkan tipe material/tanah yang tidak akan membentuk AAT jika terpapar udara pada lingkungan yang berair. Gambar 2 menunjukkan bahwa hanya sampel $\mathrm{C}$ yang memiliki nilai PKM paling besar dari sehingga pada analisis awal dinyatakan berpotensi menghasilkan AAT saat mengalami oksidasi pada kondisi berair, ternyata memiliki nilai potensi keasaman maksimum (PKM) yang lebih rendah dari nilai kapasitas penetralan asam (KPA) sehingga nilai potensi produksi asam adalah $\quad<0 \quad(-2,177) . \quad$ Evaluasi terhadap sampel B1 mengenai kemampuannya menghasilkan AAT berdasarkan rasio KPA/PKM memberikan nilai $>2(4,38)$ dengan sampel lainnya. Dengan demikian dengan nilai rasio KPA/PKM yang kurang dari $2(0,17)$ sampel C tergolong material/tanah yang akan menghasilkan AAT. Sampel $B_{1}$ yang analisis awal menunjukkan nilai $\mathrm{pH}$ pasta $<4,5$ demikian sampel B tidak berpotensi menghasilkan AAT.

\section{KESIMPULAN}

1. Evaluasi pembentukan air asam tambang untuk sampel $\mathrm{C}$ berdasarkan nilai rasio KPA/PKM diperoleh angka kurang dari $2(0,17)$ menguatkan hasil analisis parameter penentu pembentukan AAT bahwa sampel $\mathrm{C}$ adalah material penghasil AAT jika teroksidasi pada kondisi berair. 
2. Pada sampel $B_{1}$ (overburden) analisis awal berupa $\mathrm{pH}$ menunjukan nilai $\mathrm{pH}<4.5$, sehingga diduga sampel $B_{1}$ berpotensi menghasilkan AAT saat mengalami oksidasi pada kondisi berair, namun setelah dievaluasi kemampuan untuk terbentuknya AAT berdasarkan rasio KPA/PKM memberikan nilai >2 sehingga sampel $B_{1}$ tidak berpotensi membentuk AAT.

\section{DAFTAR PUSTAKA}

Achmad.R., 2004. Kimia

Lingkungan. Yogyakarta.

Badan Pusat Statistik Provinsi Papua Barat. (2012). Profil Profinsi Papua Barat Dalam Angka 2012.

Vontorova, J., Matejka, V., Dedkova, K., Praus, P. (2013). The Method for Determination of Sulfur Content in Nanocomposites. Nano Conference. Brno. Check Republic.
Manokwari: BPS Provinsi Papua Barat.

Munir, M., 2008. Pemanfaatan Abu Batu Bara (Fly Ash) untuk Hollow Block Yang Bermutu dan Aman Bagi Lingkungan. Tesis. Universitas Diponegoro . Semarang.

Sobek, A.A., Schuller, W.A., Freeman, J.R., Smith, R.M. 1978. Field and Lanoratory Methods Applicable To Overburdens and Minesosis. Industrial Environmental Research Laboratory. Ohio.

Syarif A., Said, M., Halim, A., Wiwik E. (2014). Characterization of Geochemical Disposal on Indicate and Mitigation Acid Mine Drainage at Coal Mining South Sumatera Indonesia. International Journal on Advanced Science Engineering Information Technology. 4 (4), 8689. 